\title{
Anti-Bacterial, Anti-Diarrheal, and Cytotoxic Activities of Edible Fruits in the Sundarbans Mangrove Forest of Bangladesh
}

\author{
M. Zakir Hosen, Anirban Biswas, M. Rabiul Islam, and Sheikh Julfikar Hossain \\ Biotechnology and Genetic Engineering Discipline, Life Science School, Khulna University, Khulna 9208, Bangladesh
}

\begin{abstract}
This study evaluated anti-bacterial, anti-diarrheal, and cytotoxic activities of ten edible fruits (Aegiceras corniculatum, Avicennia officinalis, Bruguiera gymnorrhiza, Ceriops decandra, Heritiera fomes, Nypa fruticans, Phoenix paludosa, Sarcolobus globosus, Sonneratia caseolaris, and Xylocarpus mekongensis) in the Sundarbans mangrove forest of Bangladesh. Highest antibacterial activity was shown for ethanol : methanol (1:1) extracts of $S$. caseolaris ( $2 \mathrm{mg} / \mathrm{disc})$, which demonstrated inhibition zones of 16.7, 17.0, 14.7, 15.7, and $15.7 \mathrm{~mm}$ against Escherichia coli, Klebsiella sp., Shigella boydii, Shigella sonnei, and Staphylococcus aureus, respectively. In mice with castor oil-induced diarrhea, S. caseolaris extract (250 mg/kg body weight) showed the highest inhibition $(87.7 \%)$ and delayed the onset time $(273 \mathrm{~min})$ of diarrheal episodes, followed by $A$. corniculatum extract (inhibition, $83.6 \%$; delayed onset time, $187.4 \mathrm{~min}$ ). S. caseolaris and A. corniculatum fruit powders were successively fractionated into $n$-hexane, diethyl ether, chloroform, ethanol, and methanol. Antidiarrheal activity significantly increased with increasing polarity of these fractions. In brine shrimp lethality assay, S. globosus extract demonstrated the highest cytotoxicity $(59.2 \mu \mathrm{g} / \mathrm{mL})$, followed by $H$. fomes $(74.1 \mu \mathrm{g} / \mathrm{mL})$ and C. decandra $(116.7 \mu \mathrm{g} / \mathrm{mL})$; however, lowest cytotoxicity was shown for A. corniculatum, A. officinalis, and S. caseolaris extracts. Mice treated with A. corniculatum extract did not experience any acute toxicity. These results demonstrate that $S$. caseolaris and $A$. corniculatum fruits have potential to treat diarrhea and may act as useful nutraceuticals.
\end{abstract}

Keywords: anti-bacteria, anti-diarrhea, cytotoxicity, mangrove fruits, the Sundarbans

\section{INTRODUCTION}

The Sundarbans, the world's largest mangrove forest, is located on the South-Western region of Bangladesh and borders the Bay of Bengal. Mangrove refers to the ecosystem of diverse groups of plants that adapt to the intersection of land and marine conditions. Various secondary metabolites are produced inside mangrove plants that enable them to adapt to this stressful environment, such as high salinity, tidal inundation, and intense sunlight. Secondary metabolites that are produced in the edible parts of the mangrove plants may be used to treat metabolic and infectious diseases in humans without inducing any toxic or hazardous effects. Previous reports have described physicochemical and antioxidant properties of the edible fruits Aegiceras corniculatum, Avicennia officinalis, Bruguiera gymnorrhiza, Ceriops decandra, Heritiera fomes, Nypa fruticans, Phoenix paludosa, Sarcolobus globosus, Sonneratia caseolaris, and Xylocarpus mekongensis, which are present in the Sundarbans mangrove forest (Hosen et al., 2020).
Moreover, studies have reported phytochemical and health promoting bioactivities of Sonneratia apetala fruits in the Sundarbans (Hossain et al., 2013; Hossain et al., 2016; Hossain et al., 2017). These edible fruits grow abundantly along the coast of Bangladesh, especially in and around the Sundarbans. Local habitants readily consume these fruits, with the highest amount of $S$. apetala, S. caseolaris, and $N$. fruticans. Due to the nutritional and health benefits of $S$. apetala fruits, it has been recommended that these fruits should be cultivated in the vast tropical coastal regions worldwide to help ensure food security, primary health care, environmental protection, and income generation, as well as for use as functional foods and as dietary supplements (Hossain et al., 2013; Hossain et al., 2016). Several studies have also reported consumption of mangrove fruits as foods and as major components in various food preparations (Brown, 2006; Chen et al., 2009; Abeywickrama and Jayasooriya, 2011).

Metabolic and infectious diseases are leading health challenges of the world (Hossain et al., 2007). Many of 
the diseases are caused by insufficient amounts of phytochemicals in diet. Dietary phytochemicals consist of an array of chemical compounds that have multiple targets of action, thereby generating synergistic beneficial effects on physiological health. Of phytochemicals consumed as part of the human diet, polyphenols are the most abundant with more than 7,000 reported. Various polyphenols have been shown to possess anti-oxidant, anti-microbial, anti-diarrheal, anti-diabetic, anti-cancer, anti-inflammatory, anti-aging, anti-neurodegenerative, and cardioprotective properties (Schuier et al., 2005; Pandey and Rizvi, 2009; Daglia, 2012). Bioactive polyphenols, such as caffeic acid, (+)-catechin, (-)-epicatechin, ellagic acid, gallic acid, and quercetin, have been reported in S. apetala fruit (Hossain et al., 2016), and S. apetala extracts strongly inhibit common pathogenic bacteria (Hossain et al., 2013; Hossain et al., 2017). Arif et al. (2014) reported that antidiabetic medicinal plants containing a high polyphenol content have strong antibacterial activities. Furthermore, earlier reports have showed that several common edible fruits in Bangladesh possess anti-amylase, anti-glucosidase, and antiallergic effects (Hossain et al., 2008), and $(+)$-catechin and its derivatives demonstrate anti-hyperglycemic effects (Hossain et al., 2002).

Intestinal bacteria and rotaviruses are major causes of diarrhea. Diarrhea accounts for more than $5 \sim 8$ million deaths each year (Victora et al., 2000; Shoba and Thomas, 2001) and is the second leading cause of death for children. Antidiarrheal agents should contain rehydration substances and agents to inhibit of causal microorganism(s). Dietary substances such as ginger, cardamom, cocoa, and black and green tea have also been used to treat diarrhea (Dillinger et al., 2000; Bruins et al., 2006; Chen et al., 2007; Rahman et al., 2008). People living in tropical coastal regions are highly dependent on forest products for their food security, primary health care, and income generation. However, meagre scientific attention has been paid on edible mangrove fruits to date. To enhance food security and primary health care of vulnerable coastal people, it is crucial to explore multipurpose uses of the coastal fruits, especially edible mangrove fruits in the Sundarbans forest. Therefore, the present research was conducted.

\section{MATERIALS AND METHODS}

\section{Chemicals and reagents}

Folin-Ciocalteu's phenol reagent and gallic acid were purchased from Sigma-Aldrich Co. (St. Louis, MO, USA). Chloroform, diethyl ether, dimethyl sulfoxide (DMSO), ethanol, $n$-hexane, hydrochloric acid, methanol, and Tween-80 were obtained from Merck KGaA (Darmstadt, Germany). Nutrient broth and nutrient agar media were purchased from HiMedia Laboratories Pvt. Ltd. (Mumbai, India).

\section{Fruit samples}

Edible fruits of A. corniculatum (L.) Blanco., A. officinalis (L.), B. gymnorrhiza (L.) Lamk., C. decandra (Griff.) Ding Hou, H. fomes Buch.-Ham, N. fruticans Wurmb., P. paludosa Roxb., S. globosus Wall., S. caseolaris (L.) Engl., and X. mekongensis Pierre were collected from the Sundarbans mangrove forest, Bangladesh from July to September, 2017. After being washed in distilled water, the edible parts were separated, and shed dried. Then, each dried fruit was pulverized into fine powder using a grinding machine, and stored in air tight containers at room temperature.

\section{Extraction}

Ten grams of powder of each fruit were placed into separate air tight bottles. Then, $200 \mathrm{~mL}$ of methanol and ethanol mixture (1:1) was added to each bottle. Mixtures were vigorously shaken $(150 \mathrm{rpm})$ at $30^{\circ} \mathrm{C}$ for $20 \mathrm{~h}$, then filtered through Whatman No. 1 filter paper (pore size 11 $\mu \mathrm{m})$. The filtrates were air dried and the extracts stored in a refrigerator at $4^{\circ} \mathrm{C}$.

\section{Fractionation}

Ten grams of powder of each fruit were successively fractionated with solvents. First, powders were fractionated by vigorously shaking (150 rpm) with $200 \mathrm{~mL}$ of $100 \%$ $n$-hexane at $30^{\circ} \mathrm{C}$ for $20 \mathrm{~h}$ in an air tight bottle. The fraction was then filtered using Whatman no. 1 filter paper, air dried, and then transferred into screw cap vials. Vials were labeled and stored at $4^{\circ} \mathrm{C}$ as $n$-hexane fraction (HEX). Diethyl ether, chloroform, ethanol, and methanol fractions (DEE, CHL, ETH, and MET, respectively) were successively prepared from residue on the filter paper.

\section{Determination of total polyphenol content}

Total polyphenol content in extracts (methanol : ethanol, 1:1) was determined according to the Folin-Ciocalteu method (Ough and Amerine, 1988) using gallic acid as the standard, expressed as mg gallic acid equivalents ( $\mathrm{mg}$ $\mathrm{GAE}$ /g of powder. One milliliter of diluted extract was mixed with $1 \mathrm{~mL}$ of Folin-Ciocalteu's reagent and vortexed for $5 \mathrm{~s}$. Then, $1 \mathrm{~mL}$ of a $10 \%(\mathrm{w} / \mathrm{v})$ sodium carbonate aqueous solution was added, the mixture was incubated at room temperature for $1 \mathrm{~h}$, and the absorbance at $700 \mathrm{~nm}$ was measured by a spectrophotometer. Each experiment was conducted three times.

\section{Antibacterial activity assays}

The bacterial strains Escherichia coli, Klebsiella sp., Shigella boydii, Shigella sonnei, and Staphylococcus aureus were obtained from International Centre for Diarrheal Disease Research' Bangladesh (ICDDR'B), Dhaka, Bangladesh. 
Bacteria were sub-cultured in nutrient agar medium at least three times with $24 \mathrm{~h}$ intervals before use. Ten microliters of culture were then transferred into a $10 \mathrm{~mL}$ nutrient broth medium and incubated at $37^{\circ} \mathrm{C}$ for $24 \mathrm{~h}$.

For susceptibility tests, nutrient agar plates were seeded by pouring culture broth to create a bacterial lawn. The bacterial population was adjusted through comparing with $0.5 \%$ McFarland standards to make $5 \times 10^{6} \mathrm{CFU} / \mathrm{mL}$. The extracts/fractions were dissolved in respective solvents to prepare the stock and added to paper discs (6 $\mathrm{mm}$ ) using a micropipette. Discs impregnated with the extracts/fractions were placed at proportionate distances from each other using sterile needles. The plates were incubated overnight $(20 \mathrm{~h})$ at $37^{\circ} \mathrm{C}$ then assessed for clear zones of inhibition around the discs.

\section{Animals}

Young Swiss-albino mice (16 22 g) of either sex were purchased from the ICDDR'B. Mice were provided with ICDDR'B formulated food and tap water ad libitum, and maintained in polypropylene cages (6 mice in each cage of $30 \mathrm{~cm} \times 15 \mathrm{~cm} \times 15 \mathrm{~cm}$ dimension) with a natural daynight cycle. All experiments were conducted in isolated and noiseless conditions in an animal house in accordance with the guidelines of the Animal Ethics Committee, Khulna University, Khulna, Bangladesh, which adheres to the EU Directive 2010 for animal experiments (Research Ref. No.: KUAEC-2017/07/02).

\section{Antidiarrheal activity assays}

Castor oil-induced diarrhea was studied as described by Shoba and Thomas (2001). Animals fasted with water for $18 \mathrm{~h}$ were randomly divided into control, positive control, and test groups (each $n=6$ ). Mice were placed into individual cages, the floors of which were lined with absorbent paper. Suspensions of extracts/fractions were prepared in water containing $0.1 \%$ Tween- 80 . The control group received distilled water containing $0.1 \%$ Tween- 80 ; the positive control group received loperamide hydrochloride [3 mg/kg body weight (b.w.)]; the test groups received the extracts/fractions. After $1 \mathrm{~h}$, each mouse was given $0.5 \mathrm{~mL}$ of castor oil with the help of a feeding needle for mice. The time elapsed between administration of castor oil and excretion of the first diarrheal stool was measured. In addition, the total numbers of characteristic diarrheal droppings were noted every half hour for 5 h. Dose-dependent antidiarrheal effects of potential fractions were studied.

\section{Cytotoxicity tests}

Brine shrimp (Artemia salina) lethality bioassay was used to assess cytotoxicity, as described by McLaughlin (1991). The eggs of $A$. salina were collected from Fisheries and Marine Resource Technology Discipline, Khulna Univer- sity, Bangladesh. Eggs were hatched into larva in the larger compartment of a rectangular tank of two unequal compartments containing artificial sea water (20 g of $\mathrm{NaCl}$ and $18 \mathrm{~g}$ of table salt in $1 \mathrm{~L}$ of distilled water). Larva were then moved to the small compartment by being attracted to the light, where they were collected to investigate the cytotoxicity of the extracts. Different concentrations $(\mu \mathrm{g} / \mathrm{mL})$ of the extracts were tested in triplicate. Extracts were dissolved in distilled water with the assistance of DMSO, ensuring that the final concentration of DMSO did not exceed $1 \%$. Vincristine sulphate (Cipla Ltd., Mumbai, India) was used as a positive control, and $1 \%$ DMSO in distilled water was used as the negative control. Survivors were counted after $24 \mathrm{~h}$, and the percentage mortality was calculated. Lethal concentrations [in which $50 \%\left(\mathrm{LC}_{50}\right)$ of the larvae died] were determined from best-fit linear lines plotting concentration verses percentage mortality.

\section{Acute toxicity tests}

Acute toxicity tests were carried out as described by Lorke (1983), with slight modifications. Young Swiss-albino mice aged $6 \sim 8$ weeks (20 30 g) were randomly divided into different groups each consisting of 6 mice. The control group (G-I) received distilled water containing $0.1 \%$ Tween- 80 and the test groups received the extract at different concentrations (500, 1,000, and 2,000 $\mathrm{mg} / \mathrm{kg}$ b.w. for G-II, G-III, and G-IV, respectively) with the help of a feeding needle. Mice were observed individually for any clinical signs of toxicity or mortality for 14 days.

\section{Statistical analysis}

Statistical analysis was performed using SPSS (version 16, SPSS Inc., Chicago, IL, USA). Results were expressed as mean \pm standard deviation (SD) for a given number of observations, $n=3 \sim 10$. One way analysis of variance (ANOVA) followed by least significant difference multiple comparison post-hoc tests were used to analyze statistical differences. Differences with $P$-values $<0.05$ were considered statistically significant.

\section{RESULTS AND DISCUSSION}

\section{Total polyphenols content}

The fruits of A. corniculatum, A. officinalis, B. gymnorrhiza, C. decandra, H. fomes, N. fruticans, P. paludosa, S. globosus, $S$. caseolaris, and $X$. mekongensis were composed of 14.9, 18.7, 21.9, 58.5, 52.7, 3.5, 29.7, 7.6, 20.7, and $17.8 \mathrm{mg} \mathrm{GAE} / \mathrm{g}$ powder, respectively. To date, no studies have shown that the barks or leaves of these edible fruit-producing plants are consumed directly or after processing. However, significantly smaller amounts of polyphenols have been re- 
ported in some edible fruits (e.g., berries and pomegranates) than their leaves (Teleszko and Wojdyło, 2015; Amri et al., 2017). The concentration of polyphenols is inversely related to the pathogenesis of various metabolic and infectious diseases (Pandey and Rizvi, 2009; Daglia, 2012). The content of polyphenols in C. decandra and $H$. fomes were similar to that in S. apetala (48 mg GAE/g powder) but less than that in Emblica officinalis fruit (89 mg GAE/g powder), an edible non-mangrove (data not published).

\section{Antibacterial activity}

The disc diffusion method was used to assay antibacterial activity of the extracts (methanol : ethanol, 1:1) of edible mangrove fruits. Clear zones around the discs indicated inhibition of growth of the test bacteria (measured in $\mathrm{mm})$. S. caseolaris extract $(2 \mathrm{mg} /$ disc) strongly inhibited the bacteria, producing clear zones diameters of 16.8 , 17.0, 14.7, 15.6, and $15.7 \mathrm{~mm}$ against E. coli, Klebsiella sp., S. boydii, S. sonnei, and S. aureus, respectively. At the same concentration, $X$. mekongensis extract showed prominent effects against $S$. aureus and $S$. sonnei, indicating clear zone diameters of 16.4 and $13.3 \mathrm{~mm}$, respectively. However, the other extracts demonstrated minimal inhibitory effects. The HEX, DEE, CHL, ETH, and MET fractions of $S$. caseolaris strongly inhibited bacterial growth. The highest degree of inhibition was seen for the ethanol fraction (clear zone diameters of 16.3, 17.4, 18.5, 16.8, and $17.5 \mathrm{~mm}$ against E. coli, Klebsiella sp., S. boydii, S. son$n e i$, and $S$. aureus, respectively, at $2 \mathrm{mg} /$ disc). However, $S$. caseolaris methanol extracts of the different parts of the plant exhibited antibacterial activity against both Grampositive and Gram-negative bacteria (Yompakdee et al., 2012). Potential antibacterial effects of fruit of S. apetala were also reported (Hossain et al., 2013; Hossain et al.,
2017), which may be due to their high content of polyphenols, especially caffeic acid, (+)-catechin, (-)-epicatechin, ellagic acid, gallic acid, and quercetin in seeds (Hossain et al., 2016). C. decandra, H. fomes, and P. paludosa extracts had high contents of polyphenols but exhibited low antibacterial effects; however, Arif et al. (2014) showed that extracts contained high polyphenol contents had strong antibacterial activities. These differences may have arisen from different interactions between polyphenols and the surfaces of bacterial cells that determine the antibacterial activity of polyphenols (Bouarab-Chibane et al., 2019) .

\section{Antidiarrheal activity}

All the mangrove fruit extracts (methanol : ethanol, 1:1) at a dose of $250 \mathrm{mg} / \mathrm{kg}$ b.w. significantly ( $P<0.05 \mathrm{vs}$. control) inhibited castor oil-induced diarrhea in mice (Fig. 1A). The highest antidiarrheal activity was demonstrated for S. caseolaris extract $(87.7 \%)$ followed by A. corniculatum extract (83.6\%). At $250 \mathrm{mg} / \mathrm{kg}$ b.w., S. caseolaris extract showed the longest delay of diarrhea onset (273 min), followed by A. corniculatum extract $(187 \mathrm{~min})$ and $\mathrm{N}$. fruticans extract (151.5 min) (Fig. 1B). Since S. caseolaris and $A$. corniculatum extracts strongly inhibited the frequency of and onset of diarrheal episodes, the extracts were fractionated into HEX, DEE, CHL, ETH, and MET fractions. In mice, the inhibitory effects of these fractions at $250 \mathrm{mg} / \mathrm{kg}$ b.w. on diarrhea are shown in Fig. 2A. These data indicated that the majority of their antidiarrheal components were polar and slightly non-polar. At $250 \mathrm{mg} / \mathrm{kg}$ b.w., the ethanol fraction of S. caseolaris showed the highest antidiarrheal activity (84.4\%) followed by the methanol fraction (77.8\%). However, for A. corniculatum, highest inhibition of diarrhea was shown for the methanol fraction (75.6\%) followed by the etha-
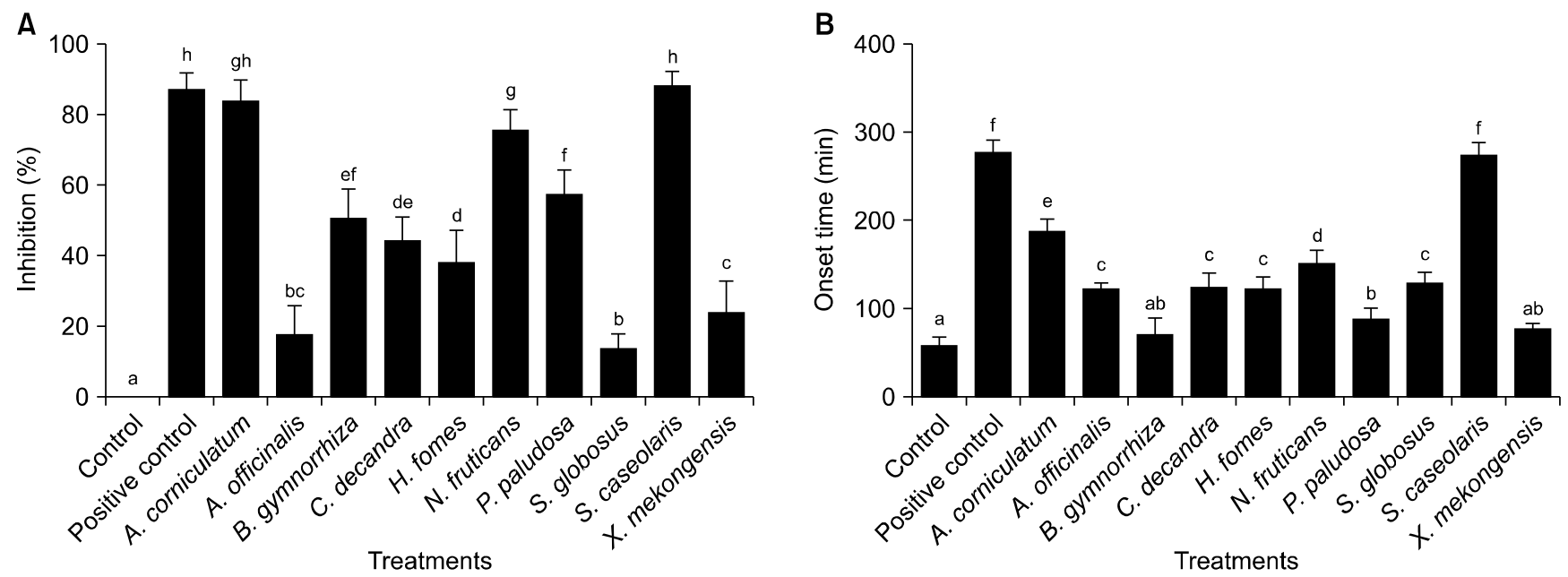

Fig. 1. Effects of edible mangrove fruits on castor oil-induced diarrhea in mice. (A) Inhibition (\%) and (B) onset time (min) of diarrhea in different treatment groups at $250 \mathrm{mg}$ extract/kg body weight (b.w.). Data are expressed as mean \pm SD ( $n=6)$. Different letters $(a-h)$ indicate significant differences compared with each other group using one way ANOVA at $P<0.05$. Positive control, loperamide $3 \mathrm{mg} / \mathrm{kg}$ b.w.. 
A

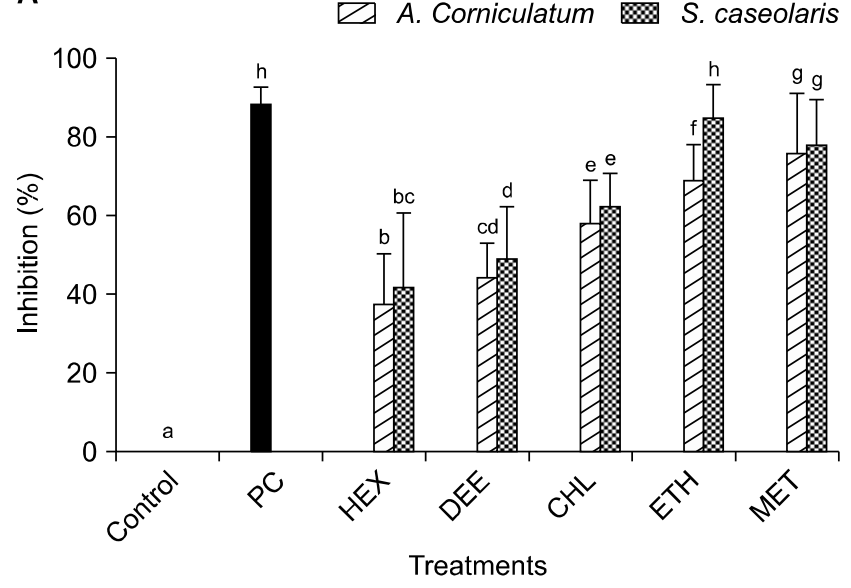

B

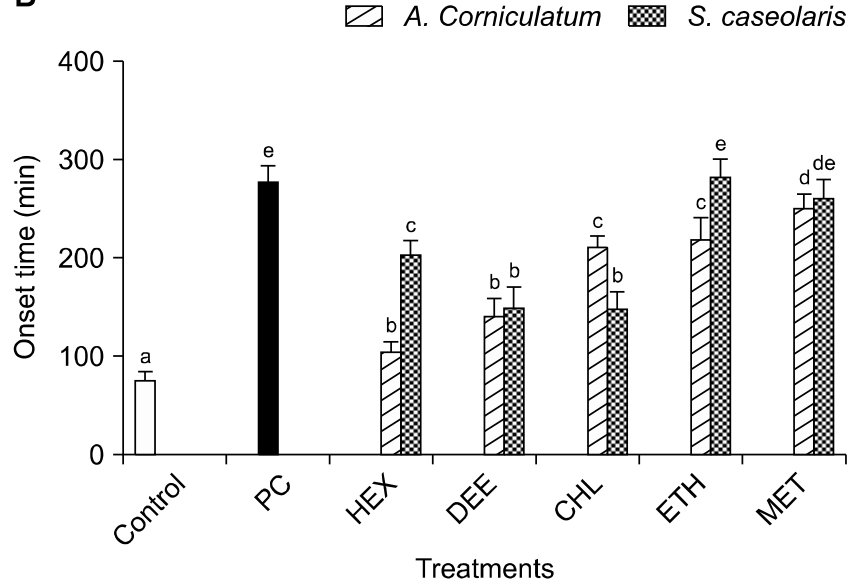

Fig. 2. Effects of different solvent [ $n$-hexane (HEX), diethyl ether (DEE), chloroform (CHL), ethanol (ETH), and methanol (MET)] fractions of the fruits on castor oil-induced diarrhea in mice. (A) Inhibition (\%) and (B) onset time (min) of diarrhea in different treatment groups at $250 \mathrm{mg}$ fraction/ $\mathrm{kg}$ b.w.. Data are expressed as mean $\pm S D(n=6)$. All data were significant compared with the control, and different letters ( $a-h)$ indicate significant differences compared to each other group using one way ANOVA at $P<0.05$. PC, positive control, loperamide $3 \mathrm{mg} / \mathrm{kg}$ b.w..
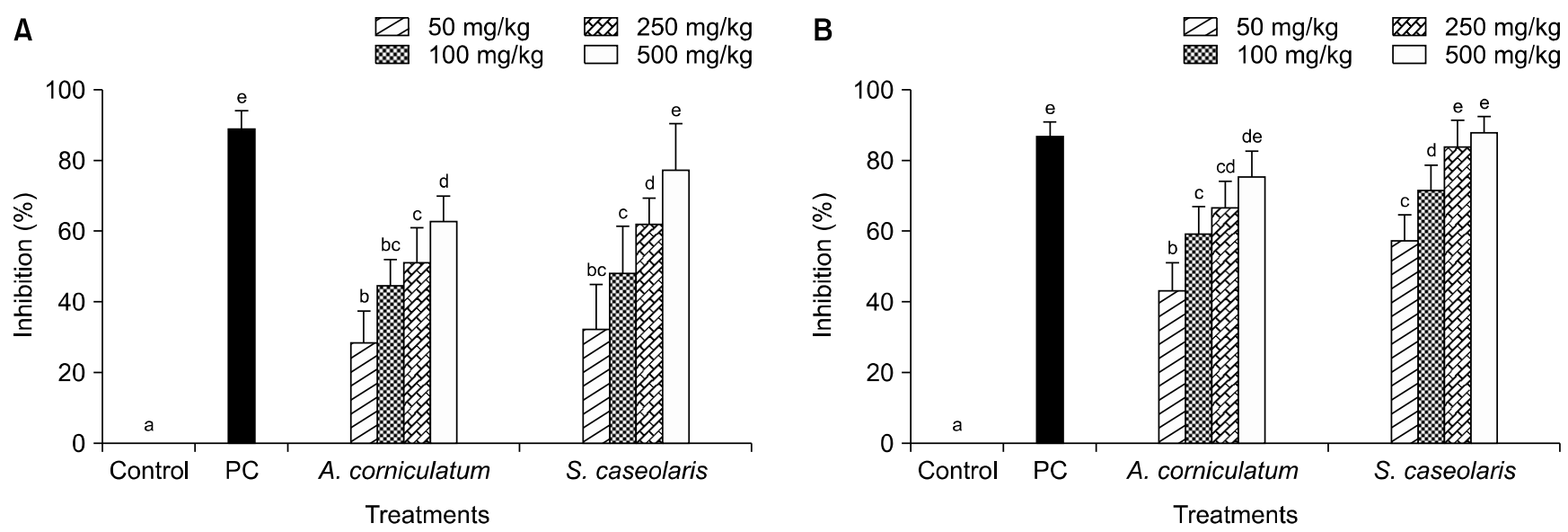

Fig. 3. Dose-dependent inhibitory effects of (A) chloroform and (B) ethanol fractions of Aegiceras corniculatum and Sonneratia caseolaris on castor oil-induced diarrhea in mice. Data are expressed as mean $\pm S D(n=6)$. All data were significant compared with the control, and different letters (a-e) indicate significant differences compared to each other group using one way ANOVA at $P<0.05$. PC, positive control, loperamide $3 \mathrm{mg} / \mathrm{kg}$ b.w..

nol fraction (69.0\%). The effects of these fractions on diarrhea onset are shown in Fig. 2B. Both the methanol and ethanol fractions strongly delayed the onset of diarrheal episodes. Dose-dependent inhibition of diarrhea using ETH and CHL fractions of S. caseolaris and A. corniculatum fruits are shown in Fig. 3.

Extracts from other parts of A. corniculatum and S. caseolaris plants have previously been shown to exhibit significant antidiarrheal activity (Ahmed et al., 2007a; Ahmed et al., 2007b; Bose et al., 2010). Furthermore, S. apetala fruit juice is used as tonic and to treat diarrhea-like diseases in coastal Bangladesh (Hossain et al., 2013). In addition, Hossain et al. (2017) reported potential antidiarrheal activity of different fractions of $S$. apetala seeds. Since ricinoleic acid in castor oil was responsible for prostaglandin-mediated diarrhea in this mice model (Pierce et al., 1971), polar and slightly non-polar compounds of the fruits were strongly involved in inhibition of prostaglandin biosynthesis and reduction of gastrointestinal motility and secretion. However, tannins, flavonoids, and reducing sugar/glycosides have been reported as potent antidiarrheal agents (Palombo, 2006). In addition, polyphenol extracts from apples have been shown to dosedependently inhibit cholera toxin-induced diarrhea, with fractions containing polymerized catechins most effectively inhibiting toxin-mediated fluid secretion (Saito et al., 2002).

\section{Cytotoxicity}

Brine shrimp lethality bioassay results are indicative of cytotoxicity (McLaughlin, 1991), therefore were used to determine cytotoxicity of extracts (ethanol:methanol, 1:1). The extracts of the A. corniculatum, A. officinalis, $B$. gymnorrhiza, C. decandra, $H$. fomes, N. fruticans, P. paludosa, 


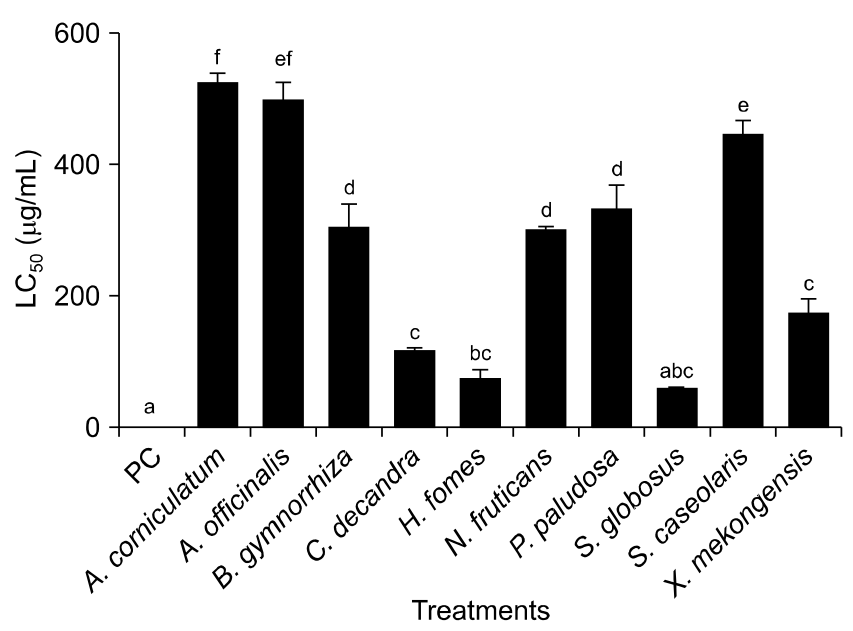

Fig. 4. $L C_{50}$ values of cytotoxic activity of different edible mangrove fruits on brine shrimp nauplii. Different letters (a-f) indicate significant differences compared to each other group using one way ANOVA at $P<0.05$. PC, positive control, vincristine sulphate $(0.45 \mu \mathrm{g} / \mathrm{mL})$.

S. globosus, S. caseolaris, and X. mekongensis fruits demonstrated LC $_{50}$ values of 524.0, 497.0, 304.5, 116.7, 74.1, 299.3, 331.4, 59.2, 444.3, and $172.0 \mu \mathrm{g} / \mathrm{mL}$, respectively, compared with $0.45 \mu \mathrm{g} / \mathrm{mL}$ for the positive control vincristine sulphate (Fig. 4). However, Ahmed et al. (2007b) reported $A$. corniculatum leaf ethanol extract show $\mathrm{LC}_{50}$ of $10 \mathrm{mg} / \mathrm{mL}$. Rieser et al. (1996) postulated that extracts with $\mathrm{LC}_{50}$ values $<250 \mu \mathrm{g} / \mathrm{mL}$ were significantly active and show potential for further investigation. Therefore, C. decandra, $H$. fomes, S. globosus, and X. mekongensis fruits are potential sources of new cytotoxic compounds. In a previous study, different $S$. apetala seed fractions showed $\mathrm{LC}_{50}$ values $<250 \mu \mathrm{g} / \mathrm{mL}$ (Hossain et al., 2017). Various flavonoids, alkaloids, tannins, and saponins have been shown to exert cytotoxic effects (Lim et al., 2007; Podolak et al., 2010; Dey et al., 2019). However, some polyphenols non-specifically bind to membrane structures and destroy cells (Hossain et al., 2002; Hossain et al., 2007).

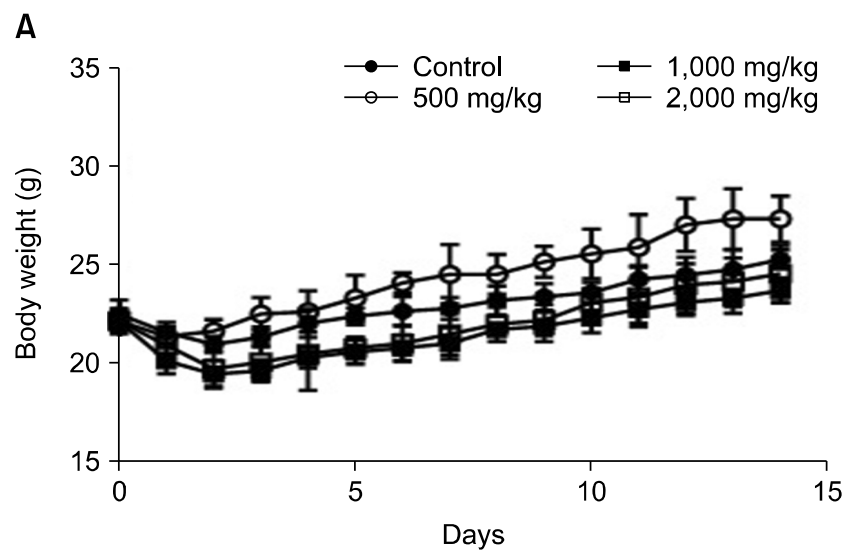

\section{Acute toxicity}

Since $S$. caseolaris and $A$. corniculatum fruits showed potential for treating diarrhea in addition to low toxicity in brine shrimp, we determined their acute toxicity. S. caseolaris fruits are readily consumed in coastal areas, although no abnormal effects on human health have yet been identified. However, A. corniculatum fruits are rarely eaten. Therefore, the A. corniculatum fruit extract (methanol : ethanol, 1:1) was used in acute toxicity test in mice. No mortality or signs of toxicity were observed within 6 $\mathrm{h}$ of continuous observation, after $24 \mathrm{~h}$, or after consecutive 14 days of oral administration at different doses (0.5, 1.0, and $2.0 \mathrm{~g} / \mathrm{kg}$ b.w.). Morphological characteristics (fur, skin, eyes, and nose) and body temperature of mice appeared to be normal. No salivation, diarrhea, lethargy, and unusual behavior were observed. Body weight gain and food and water consumption (Fig. 5) were similar to the control group, thus extracts may not affect carbohydrate, protein, or fat metabolism. In a previous study, Auletta (1995) reported that alterations in body weight gain reflect the toxicity of toxic substances. Therefore, we concluded that $A$. corniculatum fruits are non-toxic.

Of the ten edible fruits in the Sundarbans mangrove forest of Bangladesh, $S$. caseolaris showed potential to inhibit common pathogenic bacteria. A. corniculatum, and $S$. caseolaris fruit extracts $(250 \mathrm{mg} / \mathrm{kg}$ b.w.) demonstrated antidiarrheal activity similar to that of loperamide (3 $\mathrm{mg} / \mathrm{kg}$ b.w.). These two fruits showed low cytotoxicity in brine shrimp lethality bioassay, therefore showing potential to be used for the prevention and treatment of bacterial and diarrheal diseases. However, the dose of loperamide available in Bangladeshi markets is $2 \mathrm{mg}$, which was equivalent to $167 \mathrm{mg}$ of the extract produced from 1.5 and $2.2 \mathrm{~g}$ fresh fruits of A. corniculatum and S. caseolaris, respectively. These results suggest that consumption of only a few grams of the mangrove fruit may provide health and medicinal benefits for humans. Further attempts should be taken to isolate and identify potential

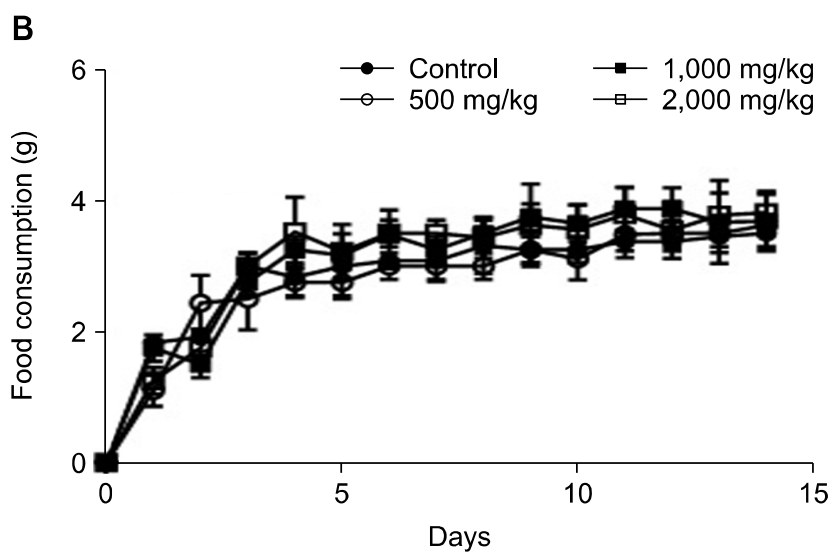

Fig. 5. Effect of different doses of Aegiceras corniculatum fruit extract (ethanol : methanol, 1:1) on (A) body weight gain (g) and (B) food consumption $(\mathrm{g})$ of mice. The control group showed non-significant differences compared to the extract-treated groups (mean $\pm \mathrm{SD} ; \mathrm{n}=6$ ) using one way ANOVA at $P<0.05$. 
health promoting compound(s) from these fruits. In addition, integrated measures are necessary to promote cultivation of the fruits in the vast tropical coastal regions of the world to meet food security and primary health care demands of coastal populations.

\section{ACKNOWLEDGEMENTS}

The present research was supported by the grant no. 6(75)/Bio-36/2015 from the University Grant Commission of Bangladesh, which is gratefully acknowledged.

\section{AUTHOR DISCLOSURE STATEMENT}

The authors declare no conflict of interest.

\section{REFERENCES}

Abeywickrama WSS, Jayasooriya MCN. Formulation and quality evaluation of cordial based on kirala (Sonneratia caseolaris) fruit. Trop Agric Res Ext. 2011. 13:16-18.

Ahmed F, Baksi B, Sadhu SK, Shahid IZ. Antinociceptive and antidiarrhoeal activities of Sonneratia caseolaris. Orient Pharm Exp Med. 2007a. 7:274-279.

Ahmed F, Mamun AHAI, Shahid IZ, Rahman AA, Sadhu SK. Antinociceptive, antidiarrhoeal and cytotoxic activity of Aegiceras corniculatum. Orient Pharm Exp Med. 2007b. 7:191-196.

Amri Z, Zaouay F, Lazreg-Aref H, Soltana H, Mneri A, Mars M, et al. Phytochemical content, fatty acids composition and antioxidant potential of different pomegranate parts: comparison between edible and non edible varieties grown in Tunisia. Int J Biol Macromol. 2017. 104:274-280.

Arif KMT, Datta RK, Sarower MG, Hossain SJ. Comparison of phenolics and antibacterial activity of commonly used antidiabetic medicinal plants in Bangladesh. PharmacologyOnLine. 2014. 1:7-15.

Auletta CS. Acute, subchronic, and chronic toxicology. In: Derelanko MJ, Hollinger MA, editors. Handbook of Toxicology. 2nd ed. CRC Press, Boca Raton, FL, USA. 1995. p 51-104.

Bose U, Bala V, Rahman AA, Shahid IZ. Evaluation of phytochemical and pharmacological propertiesof Aegiceras corniculatum Blanco (Myrsinaceae) bark. Lat Am J Pharm. 2010. 29:11261131.

Bouarab-Chibane L, Forquet V, Lantéri P, Clément Y, LéonardAkkari L, Oulahal N, et al. Antibacterial properties of polyphenols: characterization and QSAR (quantitative structureactivity relationship) models. Front Microbiol. 2019. 10:829. https://doi.org/10.3389/fmicb.2019.00829

Brown B. Cooking with mangroves: 36 Indonesian mangrove recipes: adapted with permission from Yayasan mangrove by Mangrove Action Project-Indonesia. Mangrove Action Project, Seattle, WA, USA. 2006. p 1-44.

Bruins MJ, Cermak R, Kiers JL, van der Meulen J, van Amelsvoort $\mathrm{JMM}$, van Klinken BJW. In vivo and in vitro effects of tea extracts on enterotoxigenic Escherichia coli-induced intestinal fluid loss in animal models. J Pediatr Gastroenterol Nutr. 2006. 43:459469.

Chen JC, Huang LJ, Wu SL, Kuo SC, Ho TY, Hsiang CY. Ginger and its bioactive component inhibit enterotoxigenic Escherichia coli heat-labile enterotoxin-induced diarrhea in mice. J Agric Food Chem. 2007. 55:8390-8397.

Chen L, Zan Q, Li M, Shen J, Liao W. Litter dynamics and forest structure of the introduced Sonneratia caseolaris mangrove forest in Shenzhen, China. Estuar Coast Shelf Sci. 2009. 85:241246.

Daglia M. Polyphenols as antimicrobial agents. Curr Opin Biotechnol. 2012. 23:174-181.

Dey P, Kundu A, Chakraborty HJ, Kar B, Choi WS, Lee BM, et al. Therapeutic value of steroidal alkaloids in cancer: current trends and future perspectives. Int J Cancer. 2019. 145:17311744.

Dillinger TL, Barriga P, Escárcega S, Jimenez M, Salazar Lowe D, Grivetti LE. Food of the gods: cure for humanity? A cultural history of the medicinal and ritual use of chocolate. J Nutr. 2000. 130:2057S-2072S.

Hosen MZ, Biswas A, Islam MR, Nazrul M, Bhuiyan I, Hossain S. Comparison of physicochemical and antioxidant properties of edible fruits in the Sundarbans' mangrove forest, Bangladesh. Bangladesh J Bot. 2020. 49:671-678.

Hossain SJ, Aoshima H, Koda H, Kiso Y. Review of functional studies of beverage components acting on the recombinant $\mathrm{GABA}_{\mathrm{A}}$ neuroreceptor, and $\mathrm{Na}^{+}$/glucose cotransporter-response using the Xenopus oocyte expression system and electrophysiological measurements. Food Biotechnol. 2007. 21:237-270.

Hossain SJ, Basar MH, Rokeya B, Arif KMT, Sultana MS, Rahman $\mathrm{MH}$. Evaluation of antioxidant, antidiabetic and antibacterial activities of the fruit of Sonneratia apetala (Buch.-Ham.). Orient Pharm Exp Med. 2013. 13:95-102.

Hossain SJ, Iftekharuzzaman M, Ahasanul Haque M, Saha B, Moniruzzaman M, Mahfuzur Rahman M, et al. Nutrient compositions, antioxidant activity, and common phenolics of Sonneratia apetala (Buch.-Ham.) fruit. Int J Food Prop. 2016. 19: 1080-1092.

Hossain SJ, Islam MR, Pervin T, Iftekharuzzaman M, Hamdi OAA, Mubassara S, et al. Antibacterial, anti-diarrhoeal, analgesic, cytotoxic activities, and GC-MS profiling of Sonneratia apetala (Buch.-Ham.) seed. Prev Nutr Food Sci. 2017. 22:157-165.

Hossain SJ, Kato H, Aoshima H, Yokoyama T, Yamada M, Hara Y. Polyphenol-induced inhibition of the response of $\mathrm{Na}^{+}$/glucose cotransporter expressed in Xenopus oocytes. J Agric Food Chem. 2002. 50:5215-5219.

Hossain SJ, Tsujiyama I, Takasugi M, Islam MA, Biswas RS, Aoshima $\mathrm{H}$. Total phenolic content, antioxidative, anti-amylase, anti-glucosidase, and antihistamine release activities of Bangladeshi fruits. Food Sci Technol Res. 2008. 14:261-268.

Lim DY, Jeong Y, Tyner AL, Park JH. Induction of cell cycle arrest and apoptosis in HT-29 human colon cancer cells by the dietary compound luteolin. Am J Physiol Gastrointest Liver Physiol. 2007. 292:G66-G75.

Lorke D. A new approach to practical acute toxicity testing. Arch Toxicol. 1983. 54:275-287.

McLaughlin JL. Crown gall tumours in potato discs and brine shrimp lethality: two simple bioassays for higher plant screening and fractionation. In: Hostettmann K, editor. Methods in Plant Biochemistry: Assays for Bioactivity. Academic Press, London, UK. 1991. Vol 6, p 1-32.

Ough CS, Amerine MA. Methods for analysis of musts and wine. 2nd ed. John Wiley \& Sons, Inc., Hoboken, NJ, USA. 1988. p 196-221.

Palombo EA. Phytochemicals from traditional medicinal plants used in the treatment of diarrhoea: modes of action and effects on intestinal function. Phytother Res. 2006. 20:717-724.

Pandey KB, Rizvi SI. Plant polyphenols as dietary antioxidants in human health and disease. Oxid Med Cell Longev. 2009. 2:270-278.

Pierce NF, Carpenter CC Jr, Elliott HL, Greenough WB 3rd. Effects 
of prostaglandins, theophylline, and cholera exotoxin upon transmucosal water and electrolyte movement in the canine jejunum. Gastroenterology. 1971. 60:22-32.

Podolak I, Galanty A, Sobolewska D. Saponins as cytotoxic agents: a review. Phytochem Rev. 2010. 9:425-474.

Rahman T, Rahman KA, Rajia S, Alamgir M, Khan MTH, Choudhuri MSK. Evaluation of antidiarrhoeal activity of cardamom (Elettaria cardamomum) on mice models. Orient Pharm Exp Med. 2008. 8:130-134.

Rieser MJ, Gu ZM, Fang XP, Zeng L, Wood KV, McLaughlin JL. Five novel mono-tetrahydrofuran ring acetogenins from the seeds of Annona muricata. J Nat Prod. 1996. 59:100-108.

Saito T, Miyake M, Toba M, Okamatsu H, Shimizu S, Noda M. Inhibition by apple polyphenols of ADP-ribosyltransferase activity of cholera toxin and toxin-induced fluid accumulation in mice. Microbiol Immunol. 2002. 46:249-255.
Schuier M, Sies H, Illek B, Fischer H. Cocoa-related flavonoids inhibit CFTR-mediated chloride transport across T84 human colon epithelia. J Nutr. 2005. 135:2320-2325.

Shoba FG, Thomas M. Study of antidiarrhoeal activity of four medicinal plants in castor-oil induced diarrhoea. J Ethnopharmacol. 2001. 76:73-76.

Teleszko M, Wojdyło A. Comparison of phenolic compounds and antioxidant potential between selected edible fruits and their leaves. J Funct Foods. 2015. 14: 736-746.

Victora CG, Bryce J, Fontaine O, Monasch R. Reducing deaths from diarrhoea through oral rehydration therapy. Bull World Health Organ. 2000. 78:1246-1255.

Yompakdee C, Thunyaharn S, Phaechamud T. Bactericidal activity of methanol extracts of crabapple mangrove tree (Sonneratia caseolaris Linn.) against multi-drug resistant pathogens. Indian J Pharm Sci. 2012. 74:230-236. 